\title{
Structural Studies on $t$-Carrageenan Derived Oligosaccharides and Its Application
}

\author{
Annabelle V. Briones ${ }^{*}$, Toshinori Sato ${ }^{2}$ \\ ${ }^{1}$ Industrial Technology Development, Institute DOST Complex, Taguig City, Philippines \\ ${ }^{2}$ Department of Biosciences and Informatics, Keio University, Yokohama, Japan \\ Email: avbriones2003@yahoo.com
}

Received October 18, 2013; revised November 18, 2013; accepted November 25, 2013

Copyright (C) 2014 Annabelle V. Briones, Toshinori Sato. This is an open access article distributed under the Creative Commons Attribution License, which permits unrestricted use, distribution, and reproduction in any medium, provided the original work is properly cited. In accordance of the Creative Commons Attribution License all Copyrights (C) 2014 are reserved for SCIRP and the owner of the intellectual property Annabelle V. Briones, Toshinori Sato. All Copyright (C) 2014 are guarded by law and by SCIRP as a guardian.

\begin{abstract}
Mild hydrochloric acid hydrolysis of $\boldsymbol{t}$-carrageenan from Eucheuma spinosum yielded two oligosaccharides of sulfated tetrasaccharide structure. These were characterized by Fourier Transform Infrared Spectroscopy (FTIR), Nuclear Magnetic Resonance (NMR) and Electrospray Ionization Mass Spectrometry (ESIMS). Both oligosaccharides have structure of $\beta$-D-galactopyranose(Galp)4S-(1 $\rightarrow 4)-\alpha$-D-AnGalp2S-(1 $\rightarrow 3)$ - $\beta$-D-galactopyranose Galp)4S-(1 $\rightarrow 4)-\alpha$-D-AnGalp2S-(1 $\rightarrow 3)$. Application of the resulting oligosaccharides on protein delivery system in terms of encapsulation efficiency was performed.
\end{abstract}

\section{KEYWORDS}

\section{Carrageenan; Oligosaccharides; Protein Delivery; Hydrolysis}

\section{Introduction}

Oligosaccharides which are sugars of shorter chains derived from larger polysaccharides or being synthesized are now of scientific interest for therapeutics and medical applications [1-8]. It can be obtained by direct extraction from natural sources, or chemical processes such as hydrolyzation of polysaccharides or chemical synthesis from disaccharides [9]. In this paper, oligosaccharides were derived by mild hydrolysis from $l$-carrageenan. Previous studies showed that by using mild hydrolysis, oligosaccharides can be derived from $\kappa$-carrageenan $[10,11]$. There were no studies reported yet on deriving oligosaccharides from $l$-carrageenan using mild acid hydrolysis. The published method was by enzymatic hydrolysis [12] and also used in $\kappa$-carrageenan and $\lambda$-carrageenan [13, 14]. Hence, the aim of this study is to prepare oligosaccharides from $\boldsymbol{l}$-carrageenan by mild acid hydrolysis and evaluate its potential use for protein delivery system.

Numerous studies were also made on the use of carrageenan for controlled release of drugs [15-21]. Carra-

${ }^{*}$ Corresponding author. geenan has also been cross-linked with polyacrylic acidco-poly-2-acrylamido-2-methylpropanesulfonic acid (PAA - co-PAMPS) to form a biodegradable hydrogel as a candidate for a drug delivery system [22] and interacted with chitosan to form a polyelectrolyte complex to encapsulate GOD [23]. There has been no study done on the use of oligosaccharides derived from $l$-carrageenan for protein delivery system thus in this study, its application for protein delivery system was preliminary investigated.

\section{Experimental}

\subsection{Mild Hydrolysis of $\imath$-Carrageenan}

l-Carrageenan (Benvisco SI-100, Lot No. M1400-1, average $\mathrm{MW}=560 \mathrm{kDa}$ ) was obtained from Shemberg Biotech Corporation (Carmen, Cebu, Philippines, 6005). Hydrolysis was carried out by dissolving $10 \mathrm{~g}$ of $t$-Carrageenan with $500 \mathrm{~mL}$ of $0.1 \mathrm{M}$ hydrochloric acid and heated at $60^{\circ} \mathrm{C}$ for 3 hours. The degradation was terminated by neutralization with $0.1 \mathrm{M} \mathrm{NaOH}$, then filtered followed by desalting and freeze drying. Separation and 
purification of $t$-carrageenan oligosaccharides were done following the method of Guangli Yu et al. [11].

\subsection{Characterization of Oligosaccharides}

The analysis of physicochemical properties of the oligosacchrides were based on the procedures found in USP XXII [24]. Fourier Transform Infrared Spectra (FT-IR) for oligosaccharides were measured using RX-1 Perkin Elmer FTIR spectrometer prepared as thin film on a potassium bromide pellet. The oligosaccharides were also analyzed by ${ }^{13} \mathrm{C}$ Nuclear Magnetic Resonance (NMR) spectroscopy (JEOL Lambda LA 400 NMR spectrometer) and Electrospray Ionization Mass Spectrometry (ESIMS) 3000 plus Esquire mass selective detector (Bruker Daltonics) using a 1:1 mixture of water and acetonitrile.

\subsection{Application of Oligosaccharides in Protein Delivery System}

The oligosaccharide solution and protein complex was prepared following the procedure of A.V. Briones and T. Sato [25] with some modification. Chitosan (45 KDa) solution was prepared at $1 \mathrm{mg} / \mathrm{mL}$ in Phosphate Buffer Solution (PBS) at $\mathrm{pH}$ 6.5. Carrageenan $(1 \mathrm{mg} / \mathrm{mL})$, Trisodium Citrate $(1 \mathrm{mg} / \mathrm{mL})$ and BSA $(4 \mathrm{mg} / \mathrm{mL})$ solutions were prepared in MilliQ water. BSA solution was added to chitosan solution, mixed thoroughly followed by addition of trisodium citrate solution and allowed to stabilize at room temperature for 15 minutes. Carrageenan solution was then slowly added to the mixture, mixed again followed by another 15 minutes stabilization at room temperature. Final concentration of BSA in the complex was $1 \mathrm{mg} / \mathrm{mL}$. Thereafter the final mixture was incubated for 24 hours at $4^{\circ} \mathrm{C}$ with shaking at $200 \mathrm{rpm}$ [25]. After incubation of the complex, the solution was centrifuged at $10,000 \mathrm{rpm}$ for 20 minutes at $4^{\circ} \mathrm{C}$. The resulting supernatant was then assayed for its protein content following the manufacture's instruction (Bio-Rad Laboratories, Japan). All experiments were performed in triplicate. To determine the efficacy of the complex of $l$-car- rageenan oligosaccharide and chitosan to entrap the protein (BSA) the encapsulation efficiency (E.E.) was measured according to the equation (at the end of the page). Where the initial concentration of protein is the amount of BSA used $(1 \mathrm{mg} / \mathrm{mL})$; and the protein reading from assay is the amount of BSA recovered from the complex after assay.

\section{Results and Discussion}

\subsection{Characterization of Oligosaccharides}

The structure of $t$-carrageenan is composed of $(1 \rightarrow 3)-\beta$ D-galactopyranose(Galp)4S-( $1 \rightarrow 4)-\alpha$-D-AnGalp2S- $(1 \rightarrow)$ $\mathrm{n}$ as shown in Figure 1 [26] while oligosaccharides are composed of longer chains of monosaccharide (between two and nine) units bound together by glycosidic bonds.

In this study, two oligosaccharides (F1 \& F2) were separated and purified. Prior to characterization of the derived oligosaccharides, the samples were subjected to thin layer chromatography analysis. Single spot was observed (data not shown) for both fractions illustrating a pure compound. IR analysis showed that the oligosaccharides contain the basic sugar unit 3,6-anydrogalactose and sulphated galactose as shown in Table 1 . The presence of ester sulfates was also confirmed.

The ESIMS spectra gave molecular ions for the sodium salt forms of both sulphated oligosaccharides. ESIMS analysis of compound F1 shown in Figure 2 and Table 2 displayed a molecular ion $(\mathrm{M}+\mathrm{Na}+)$ at $\mathrm{m} / \mathrm{z}$ 940.4 corresponding to a mass of 917.4 while compound

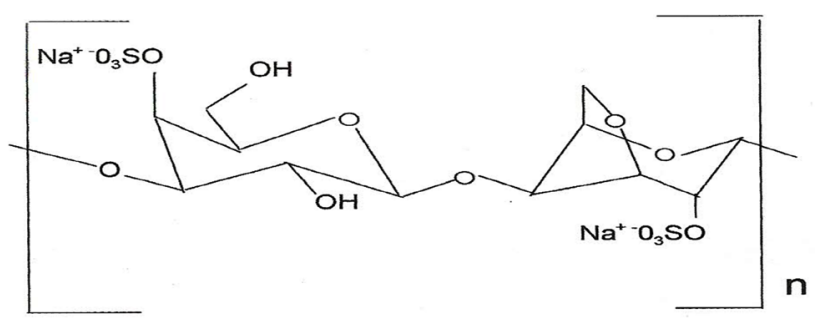

Figure 1. Disaccharide group of $\boldsymbol{t}$-carrageenan.

Table 1. Molecular assignment of carrageenan oligosaccharides by IR analysis.

\begin{tabular}{cccc}
\hline & Literature values [27] & $\begin{array}{c}\text { Lota-carrageenan } \\
\text { (unhydrolyzed) }\end{array}$ & $\begin{array}{c}\text { Carrageenan } \\
\text { oligosaccharide (F1) }\end{array}$ \\
\hline Ester sulfate & $1220-1260 \mathrm{~cm}^{-1}$ & $1254.31 \mathrm{~cm}^{-1}$ & $1231.70 \mathrm{~cm}^{-1}$ \\
oligosaccharide (F2) & $927.99 \mathrm{~cm}^{-1}$ \\
3,6-Anhydrogalactose & $928-933 \mathrm{~cm}^{-1}$ & $930.94 \mathrm{~cm}^{-1}$ & $847.82 \mathrm{~cm}^{-1}$ \\
Galactose-4-sulfate & $840-850 \mathrm{~cm}^{-1}$ & $849.07 \mathrm{~cm}^{-1}$ & $928.10 \mathrm{~cm}^{-1}$ \\
3,6-Anhydrogalactose-2-sulfate & $800-805 \mathrm{~cm}^{-1}$ & $804.33 \mathrm{~cm}^{-1}$ & $804.01 \mathrm{~cm}^{-1}$ \\
\hline
\end{tabular}

$$
\text { E.E. }(100 \%)=\frac{\text { Initial Concentration of Protein Protein Reading from Assay }}{\text { Initial Concentration of Protein }} \times 100
$$


F2 exhibited a mass of 944.1 at $\mathrm{m} / \mathrm{z} 967.1$ (refer to Table 2 and Figure 2) suggesting that both oligosaccharides are of tetrasaccharide containing two galactopyranose (Galp) residues and two 3,6 anhydrogalactopyranose (AnGalp) with four $O$-sulfo groups.

Fragmentation analysis of carrageenan oligosaccharides is illustrated in Figure 3. The fragmentation was consistent with each of the three galactose residues carrying one $O$-sulfo group.

In ${ }^{13} \mathrm{C}$ NMR analysis of the oligosaccharides, the region of 105 to 90 ppm (Figure 4), is the most informative since it is where the anomeric carbon signals are observed [12]. Unhydrolyzed iota carrageenan displays signals at around $103 \mathrm{ppm}$ for the $\beta$-Galp4S and at around $93 \mathrm{ppm}$ for the AnGalp2S [12]. Both oligosaccharides exhibited peaks at the $105 \mathrm{ppm}$ for $\beta$-Galp4S and $94.65 \mathrm{ppm}$ for AnGalp2S (Table 3). This signal at around 94.65 ppm may be attributed to the anomeric car-

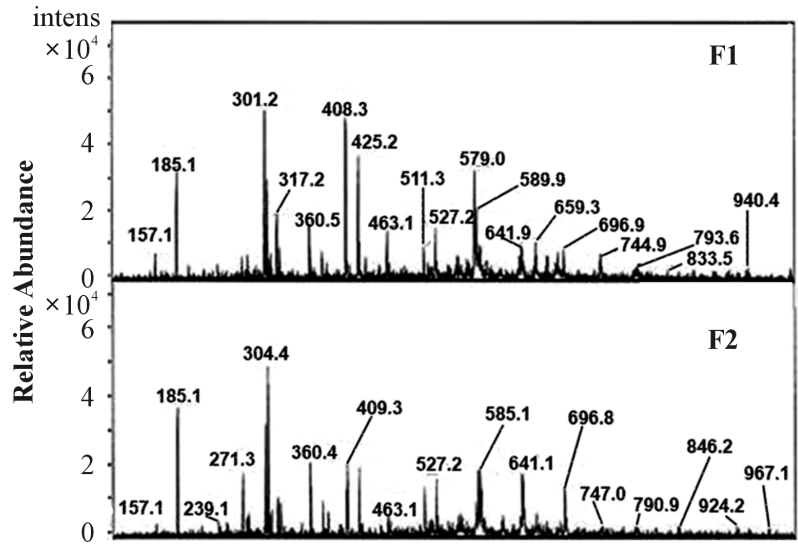

Figure 2. ESIMS analysis of oligosaccharides F1 \& F2. bon of the galactopyranosyl-4-sulfate residue at the reducing end of the chain which may have either $\alpha$ or $\beta$ conformations as observed [27]. No peaks are present at 66.4 ppm corresponding to C-4 of unsulfated Galp residues; thus, the ${ }^{13} \mathrm{C}$ spectra (Figure 4) confirm that all Gal $p$ residues contained a 4-O-sulfo group [11]. The ${ }^{13} \mathrm{C}$ NMR spectra of the degraded products clearly showed that besides the known splitting of 3,6-anhydrogalactosidic linkages, the linkage between alpha-D-galactose 2,6-disulphate and beta-D-galactose 4-sulphate is also

Table 2. Assignment of ESIMS of t-carrageenan oligosaccharides (F1 \& F2).

\begin{tabular}{|c|c|c|}
\hline \multirow{2}{*}{ Ion } & \multicolumn{2}{|c|}{$\begin{array}{c}\text { Carrageenan } \\
\text { oligossacharide }\end{array}$} \\
\hline & F1 & F2 \\
\hline $\mathrm{M}+\mathrm{Na}^{+}$ & 940.4 & 967.1 \\
\hline $\mathrm{M}-6 \mathrm{Na}^{+}{ }_{2} \mathrm{H}_{2} \mathrm{O}$ & 833.5 & \\
\hline $\mathrm{M}-\mathrm{Na}^{+} \mathrm{H}_{2} \mathrm{O}$ & & 924.2 \\
\hline $\mathrm{M}-2 \mathrm{NA}^{+}{ }_{2} \mathrm{H}_{2} \mathrm{O}$ & & 846.2 \\
\hline $\mathrm{M}-9 \mathrm{Na}^{+}-6 \mathrm{H}_{2} \mathrm{O}$ & 696.7 & 696.7 \\
\hline M-Galp4SAnGalp2S-Na $-2 \mathrm{H}_{2} \mathrm{O}$ & 511.3 & 511.3 \\
\hline Galp4SAnGalp2SGalp4SAnGalp2S-4Na ${ }^{+}$ & 940.4 & \\
\hline Galp4SAnGalp2SGalp4SAnGalp2S-3Na ${ }^{+}$ & & 967.1 \\
\hline Galp4SAnGalp2S-N $\mathrm{N}^{+}-2 \mathrm{H}_{2} \mathrm{O}$ & 527.2 & 527.2 \\
\hline Galp4S-Na $-\mathrm{H}_{2} \mathrm{O}$ & 239.2 & \\
\hline Galp $4 \mathrm{~S}-2 \mathrm{Na}^{+}-\mathrm{H}_{2} \mathrm{O}$ & & 239.2 \\
\hline AnGalp2S-NaSO ${ }_{3}+\mathrm{H}^{+}$ & 157.1 & 157.1 \\
\hline
\end{tabular}

F1

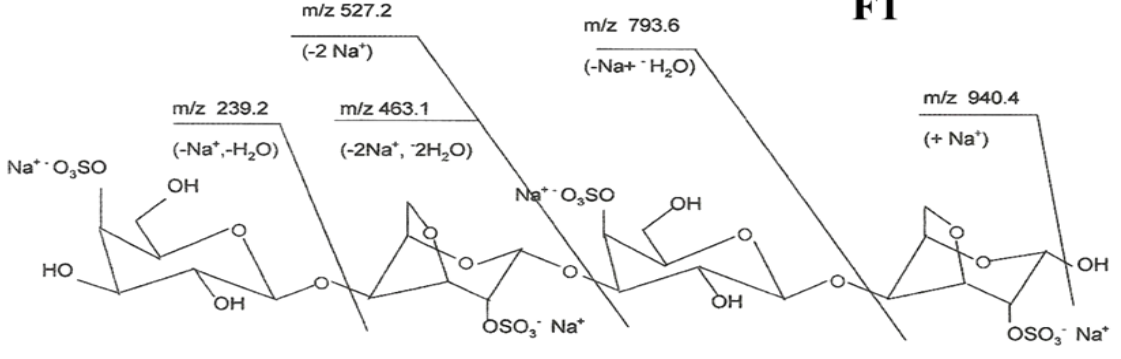

F2

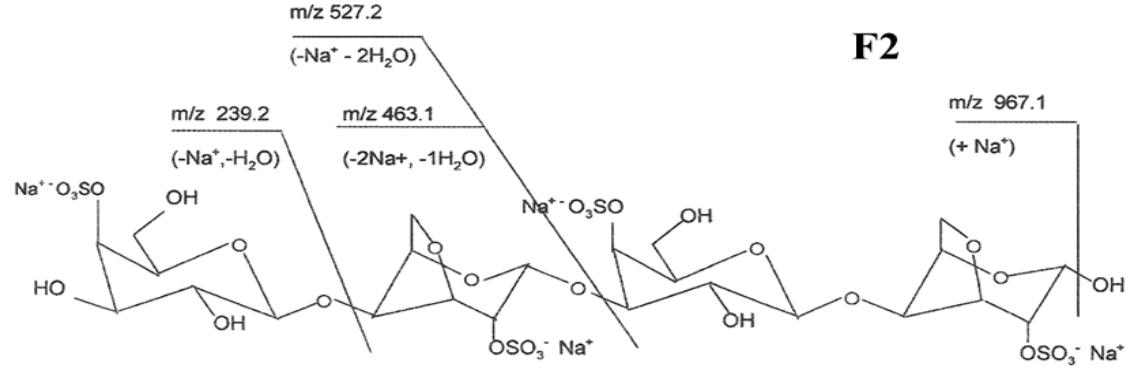

Figure 3. Fragmentation analysis of oligosaccharides F1 \& F2. 
Table $3 .{ }^{13} \mathrm{C}$ NMR chemical shifts of the $\boldsymbol{t}$-carrageenan oligosaccharides (F1 \& F2).

\begin{tabular}{ccccccc}
\hline \multirow{2}{*}{ Residue } & \multicolumn{6}{c}{ Chemical shift (ppm) } \\
\cline { 2 - 7 } & C1 & C2 & C3 & C4 & C5 & C6 \\
\hline Oligosaccharide F1 & & & & & & \\
$\beta$-Galp4S & 105.08 & 71.60 & 77.30 & 74.50 & 79.41 & 63.70 \\
AnGalp2S & 94.64 & 72.31 & 80.90 & 80.27 & 77.40 & 63.78 \\
Oligosaccharide F2 & & & & & & \\
$\beta$-Galp4S & 105.05 & 71.60 & 77.29 & 74.59 & 79.40 & 63.70 \\
AnGalp2S & 94.65 & 72.23 & 80.91 & 80.30 & 77.39 & 64.01 \\
\hline
\end{tabular}
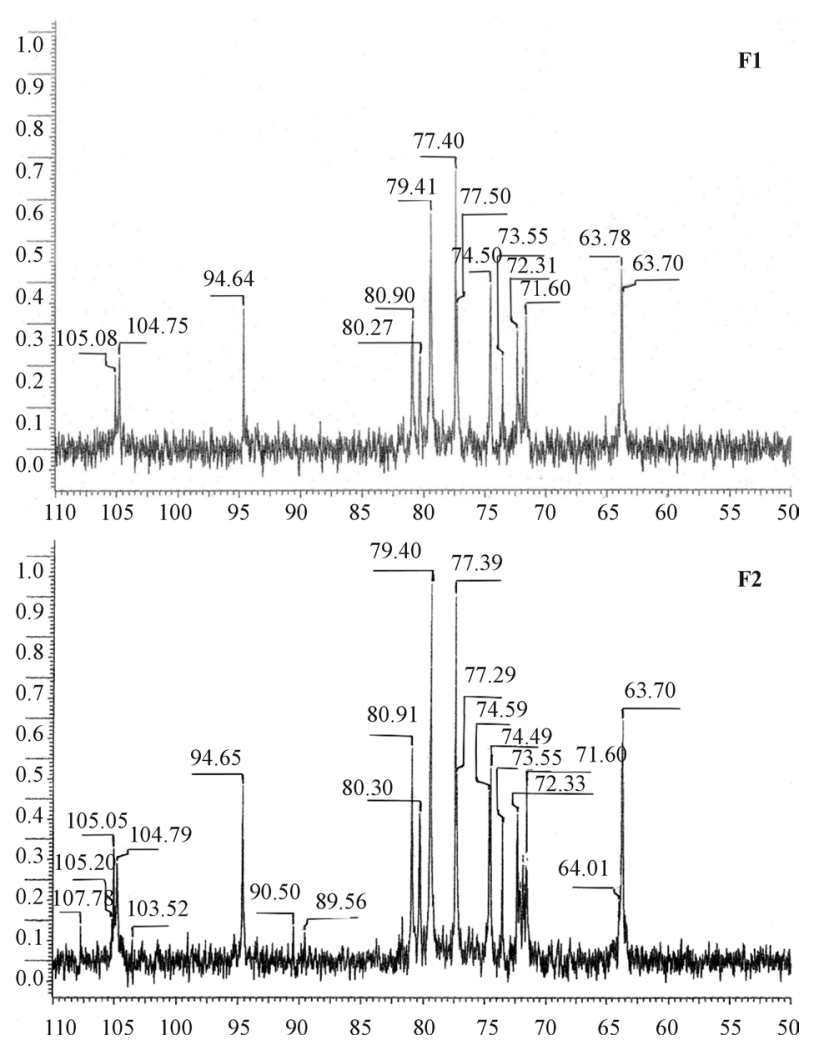

Figure $4 .{ }^{13} \mathrm{C}$ NMR spectra of the $\boldsymbol{t}$-carrageenan oli gosaccharides (F1 \& F2).

cleaved. One-dimensional 1H NMR confirmed the high level of purity of both oligosaccharides (Figures 5 \& 6). NMR and MS analysis definitively establish the structures of the oligosaccharides F1 \& F2 to be sulfated tetrasaccharide of the structure: $\beta$-D-galactopyranose (Galp) $4 \mathrm{~S}$ - $(1 \rightarrow 4)-\alpha$-D-AnGalp2S-( $1 \rightarrow 3)$ - $\beta$-D-galactopyranose (Galp)4S-( $1 \rightarrow 4)-)-\alpha$-D-AnGalp2S-( $1 \rightarrow 3)$.

\subsection{Application of Oligosaccharides in Protein Delivery System}

The oligosaccharides were evaluated for their ability to

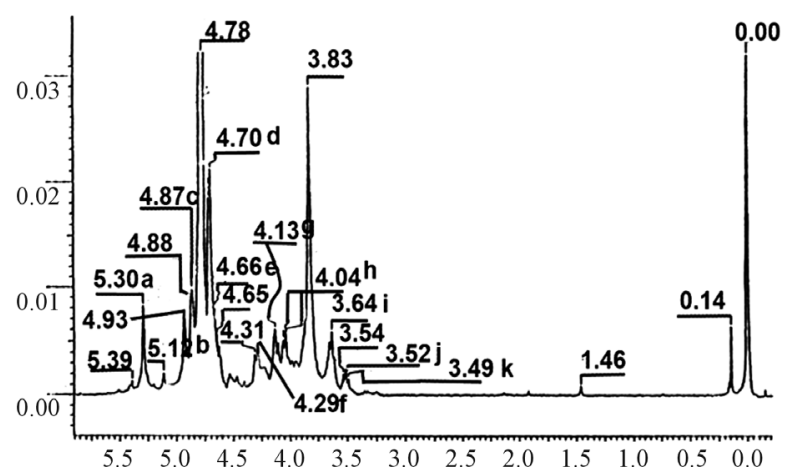

Figure 5. One dimensional 1H NMR spectrum of $\mathbf{t}$-carrageenan oligosaccharide F1. Signals: (a) $\alpha$-Galp-4S H-1; (b) AnGalp2S H-1; (c) $\alpha$-Galp-4S H-4; (d) $\beta$-Galp-4S H-4; (e) $\beta$-Galp-4S H-1; (f) AnGalp2S H-6b; (g) AnGalp2S H-2; (h) AnGalp2S H-6a; (i) $\beta$-Galp-4S H-5; (j) $\beta$-Galp-4S H-2.

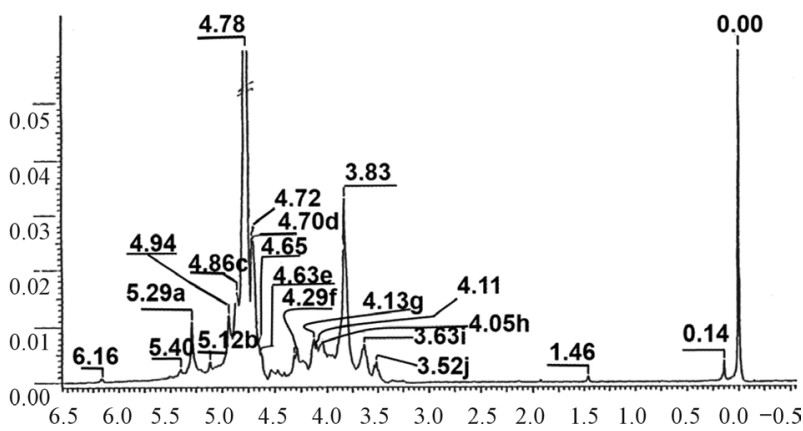

Figure 6. One dimensional 1H NMR spectrum of $\mathbf{t}$-carrageenan oligosaccharide F2. Signals: (a) $\alpha$-Galp-4S H-1; (b) AnGalp2S H-1; (c) $\alpha$-Galp-4S H-4; (d) $\beta$-Galp-4S H-4; (e) $\beta$-Galp-4S H-1; (f) AnGalp2S H-6b; (g) AnGalp2S H-2; (h) AnGalp2S H-6a; (i) $\beta$-Galp-4S H-5; (j) $\beta$-Galp-4S H-2.

form a complex with chitosan to encapsulate Bovine Serum Albumin (BSA) as the protein model. Chitosan is known to form stable complexes with carrageenans [28]. The maximum yield of complex formation was observed for the molar mixing ratio of $1: 1$, which suggests a stoichiometric anion-cation interaction [28]. The complexation of chitosan and carrageenan was due to the opposite charges between the positively charged amine groups $\left(\mathrm{NH}_{3}\right)$ in chitosan and the negatively charged sulfate groups $\left(\mathrm{SO}_{4}\right)$ in carrageenan. In this study, different charge ratios (+/-) of $0.5,1,3,5$, 7 were prepared to determine the encapsulation efficiency of the polyelectrolyte complex of $\boldsymbol{t}$-carrageenan oligosaccharide/chitosan. In previous study [25], chitosan and carrageenan complex were formed by electrostatic interaction without using a cross-linker. Here, a crosslinker which is trisodium citrate was used in the preparation of the complex. As shown in Figure 7, the complex of chitosan/ $l$-carrageenan oligosaccharide had the highest encapsulation efficiency of $67.07 \%$ at a charge ratio of 5 while chitosan with the cross-linker had the highest encapsulation effi- 


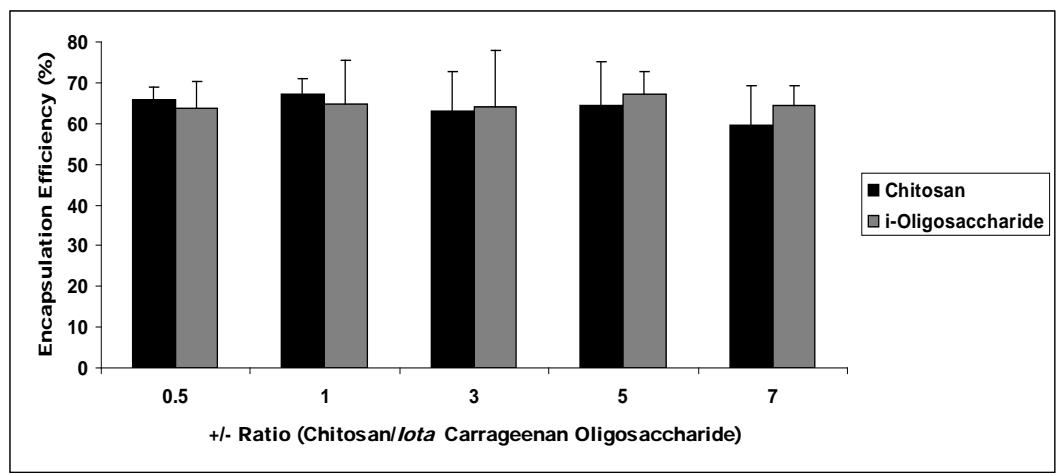

Figure 7. A. Efficiency of chitosan/ $\boldsymbol{l}$-carrageenan oligosaccharide complex to encapsulate BSA (1 mg/mL) at different charge $(+/-)$ ratios. The values represent the mean $\pm S D, n=4$. BSA indicates bovine serum albumin.

ciency of $67.14 \%$ at a charge ratio of 1 . In previous study, the encapsulation efficiency of chitosan without the cross linker is only $10 \%$ while the un-hydrolyzed iota-carrageenan is $24 \%$ [25]. With the use of a cross linker, the encapsulation efficiency increases. However, the complex of chitosan with un-hydrolyzed iota-carrageenan has an encapsulation efficiency of $73.0 \%$ at charge ratio of 3 [25].

The encapsulation efficiency of BSA using the complex of chitosan and carrageenan (hydrolyzed and unhydrolyzed) is dependent on the charge ratios and its molecular weight. The polyion complex (chitosan/carrageenan) is more efficient than using just one polymer without the use of a crosslinking agent. The electrostatic interaction of the sulphate group of carrageenan and the amine group of chitosan makes a better entrapment of BSA than chitosan alone. Charge ratios (+/-) of $3 \& 5$ were the most efficient as compared to $1 \& 7$ ratios using unhydrolyzed carrageenan [25] while the $l$-carrageenan oligosaccharide tends to favor 5 \& 7 charge ratios (Figure 7). The entrapment of BSA with the complex is due to ionic interaction. The isoelectric point of BSA is 4.8 [12] and the $\mathrm{pH}$ used in this study for complex formation was pH 6.0 which is above the isoelectric point of BSA. At this condition, the BSA would be predominantly negatively charged thus would ionically interact with chitosan competing with the more anionic carrageenan.

\section{Summary and Conclusion}

The study was able to isolate and characterize two oligosaccharides from iota carrageenan using mild acid hydrolysis. The oligosaccharides were of be sulfated tetrasaccharide of the structure: $\beta$-D-galactopyranose(Galp) $4 \mathrm{~S}$ - $(1 \rightarrow 4)-\alpha$-D-AnGalp2S-( $\rightarrow 3)$ - $\beta$-D-galactopyranose $(\mathrm{Gal} p) 4 \mathrm{~S}-(1 \rightarrow 4)-)-\alpha$-D-AnGalp2S-( $\rightarrow 3)$. The oligosaccharides have the ability to form a complex with chitosan to encapsulate Bovine Serum Albumin (BSA) and have the potential to be used in protein delivery system.

\section{Acknowledgements}

Sincere thanks to Japan Society for the Promotion of Science (JSPS) for the financial support from the grant under the RONPAKU dissertation program and Keio University, as well as to the Industrial Technology Development Institute, and the Department of Science \& Technology, Manila, Philippines.

\section{REFERENCES}

[1] H. Yuan, J. Song, X. Li, N. Li and J. Dai, "Immunomodulation and Antitumor Activity of [кappa]-Carrageenan Oligosaccharides," Cancer Letters, Vol. 243, No. 2, 2006, pp. 228-234.

http://dx.doi.org/10.1016/j.canlet.2005.11.032

[2] N. Volpi and F. Maccari, "Structural Characterization and Antithrombin Activity of Dermatan Sulfate Purified from Marine Clam Scapharca inaequivalvis," Glycobiology, Vol. 19, No. 4, 2009, pp. 356-367. http://dx.doi.org/10.1093/glycob/cwn140

[3] H. Zhao, H. Liu, Y. Chen, X. Xin, J. Li, Y. Hou, Z. Zhang, X. Zhang, C. Xie and M. Geng, "Oligomannurarate Sulfate, A Novel Heparanase Inhibitor Simultaneously Targeting Basic Fibroblast Growth Factor, Combats Tumor Angiogenesis and Metastasis," Cancer Research, Vol. 66, No. 17, 2006, pp. 8779-8787. http://dx.doi.org/10.1158/0008-5472.CAN-06-1382

[4] J. H. Fitton, M. R. Irhimeh and J. Teas, "14 Marine Algae and Polysaccharides with Therapeutic Applications,” In: C. J. Barrow and F. Shahidi, Eds., Marine Nutraceuticals and Functional Foods, CRC Press, 2008, p. 345.

[5] Q. H. Hou, W. D. Song, H. Wang and L. L. Ji, “Antidiabetic Effect of Thallus laminariae Oligosaccharide on Type 2 Diabetic Rats,” Journal of Zhanjiang Ocean University, Vol. 29, No. 4, 2009, pp. 46-50.

[6] N. R. Sudarshan, D. G. Hoover and D. Knorr, "Antibacterial Action of Chitosan,” Food Biotechnology, Vol. 6, No. 3, 1992, pp. 257-272. http://dx.doi.org/10.1080/08905439209549838

[7] M. N. Alekshun and S. B. Levy, "Targeting Virulence to Prevent Infection: To Kill or Not to Kill?” Drug Discovery Today: Therapeutic Strategies, Vol. 1, No. 4, 2004, 
pp. 483-489. http://dx.doi.org/10.1016/j.ddstr.2004.10.006

[8] W. Xie, P. Xu and Q. Liu, "Antioxidant Activity of Water-Soluble Chitosan Derivatives,” Bioorganic \& Medicinal Chemistry Letters, Vol. 11, No. 13, 2001, pp. 16991701. http://dx.doi.org/10.1016/S0960-894X(01)00285-2

[9] J. Ji, L. C. Wang, H. Wu and H. M. Luan, "Bio-Function Summary of Marine Oligosaccharides,” International Journal of Biology, Vol. 3, No. 1, 2011, pp. 75-86.

[10] H. Yuan and J. Song, "Preparation, Structural Characterization and in Vitro Antitumor Activity of Kappa-Carrageenan Oligosaccharide Fraction from Kappaphycus striatum,” Journal of Applied Phycology, Vol. 17, No. 1, 2005, pp. 7-13. http://dx.doi.org/10.1007/s10811-005-5513-8

[11] G. Yu, H. Guan, A. S. Ioanoviciu, S. A. Sikkander, C. Thanawiroon, J. K. Tobacman, T. Toida and R. J. Linhardt, "Structural Studies on $\kappa$-Carrageenan Derived Oligosaccharides," Carbohydrate Research, Vol. 337, 2002, pp. $433-440$. http://dx.doi.org/10.1016/S0008-6215(02)00009-5

[12] B. M. Henares, E. P. Enriquez, F. M. Dayrit and N. R. L. Rojas, "Iota-Carrageenan Hydrolysis by Pseudoalteromonas carrageenovora IFO12985," Philippine Journal of Science, Vol. 139, No. 2, 2010, pp. 131-138.

[13] X. Hu, X. Jiang, E. Aubree, P. Boulenguer and A. T. Critchley, "Preparation and in Vivo. Antitumor Activity of $\kappa$-Carrageenan Oligosaccharides," Pharmaceutical Biology, Vol. 44, No. 9, 2006, pp. 646-650. http://dx.doi.org/10.1016/S0008-6215(02)00009-5

[14] M. Guibet, S. Colin, T. Barbeyron, S. Genicot, B. Kloareg, G. Michel and W. Helbert, "Degradation of $\lambda$-carrageenan by Pseudoalteromonas carrageevora $\lambda$-carrageenase: A New Family of Glycoside Hydrolases Unrelated to $\kappa$ - and $l$-Carrageenases," Biochemical Journal, Vol. 404, 2007, pp. 105-114. http://dx.doi.org/10.1042/BJ20061359

[15] C. Aguzzi, M. C. Bonferoni, M. R. O. Fortich, S. Rossi, F. Ferrari and C. Caramella, "Influence of Complex Solubility on Formulations Based on Lambda Carrageenan and Basic Drugs,” AAPS PharmSciTech, Vol. 3, No. 3, 2003, pp. 83-89. http://dx.doi.org/10.1007/BF02830625

[16] A. M. Garcia and E. S. Ghaly, "Preliminary Spherical Agglomerates of Water Soluble Drug Using Natural Polymer and Cross-Linking Technique,” Journal of Controlled Release, Vol. 4, No. 30, 1996, pp. 179-186. http://dx.doi.org/10.1016/0168-3659(95)00179-4

[17] O. Sipahigil and B. Dortunc, "Preparation and in Vitro Evaluation of Verapamil $\mathrm{HCl}$ and Ibuprofen Containing Carrageenan Beads,” International Journal of Pharmaceutics, Vol. 228, No. 1, 2001, pp. 119-128. http://dx.doi.org/10.1016/S0378-5173(01)00814-6
[18] Y. Ozsoy and N. Bergisadi, "Preparation of Mefenamic Acid Sustained Release Beads Based on Kappa-Carrageenan,” Bollettino Chimico Farmaceutico, Vol. 139, No. 3, 2000, pp. 120-123.

[19] M. R. Mangione, D. Giacomazza, G. Cavallaro, D. Bulone, V. Martorana and P. L. San Biagio, "Relation between Structural and Release Properties in a Polysaccharide Gel System,” Biophysical Chemistry, Vol. 129, No. 1, 2007, pp. 18-22.

http://dx.doi.org/10.1016/j.bpc.2007.04.013

[20] G. Ruiz and E. S. Ghaly, "Mucoadhesive Delivery Systems Using Carrageenan and Eudragit RLPO," VitaeColumbia, Vol. 13, No. 1, 2006, pp. 31-39.

[21] V. K. Gupta, M. Hariharan, T. A. Wheatley and J. C. Price, "Controlled-Release Tablets from Carrageenans: Effect of Formulation, Storage and Dissolution Factors," European Journal of Pharmaceutics and Biopharmaceutics, Vol. 51, No. 3, 2001, pp. 241-248. http://dx.doi.org/10.1016/S0939-6411(01)00135-7

[22] A. Pourjavadi, Sh. Barzegar and F. Zeidabadi, "Synthesis and Properties of Biodegradable Hydrogels of $\kappa$-Carrageenan Grafted Acrylic Acid-co-2-acrylamido-2-methylpropanesulfonic Acid as Candidates for Drug Delivery Systems," Reactive and Functional Polymers, Vol. 67, No. 7, 2007, pp. 644-654. http://dx.doi.org/10.1016/j.reactfunctpolym.2007.04.007

[23] WHO, "Evaluation of Certain Food Additives and Contaminants," Sixty-Eighth Report of the Joint FAO/WHO Expert Committee on Food Additives, WHO Technical Report Series 947, 2007, pp. 32-33.

[24] W. M. Heller, "The United States Pharmacopeia,” 22nd Edition, 12601Twinbrook Parkway, Rockville, 1990.

[25] A. V. Briones and T. Sato, "Ability of Chitosan/Carrageenan Complex to Encapsulate Bovine Serum Albumin (BSA) for Potential Use in Protein Delivery," Asian Journal of Biological and Life Sciences, Vol. 2, No. 2, 2013, pp. 163-169.

[26] S. H. Knutsen, D. E. Myslabodski, B. Larsen and A. I. Usov, "A Modified System of Nomenclature for Red Algal Galactans,” Botanica Marina, Vol. 37, No. 2, 1994, pp. 163-169.

http://dx.doi.org/10.1515/botm.1994.37.2.163

[27] C. W. Greer, C. Rochas and W. Yaphe, "Iota-Carrageenan Oligosaccharides as Model Compounds for Structural Analysis of Iota-Carrageenan by 13C-NMR Spectroscopy,” Botanica Marina, Vol. 28, 1985, pp. 9-14. http://dx.doi.org/10.1515/botm.1985.28.1.9

[28] C. Mireles, M. Martino, J. Bouzas and J. A. Torres, "Complex Formation of Chitosan and Naturally Occurring Polyanions,” In: C. J. Brine, P. A. Sandford and J. P. Zikakis Eds., Advances in Chitin and Chitosan, Elsevier Applied Science, London, 1991, pp. 506-515. 